\title{
Effect of Colour Symbolism of Native Culture on Image Display in Association Experiment
}

\author{
Elena Mikitchenko \\ Sanya University \\ Sanya, China
}

\begin{abstract}
The influence of colour symbolism and colour archetypes of the native culture on beginnings of individual conceptualization and representations. Comparison of the related surveys conducted among Chinese and Russian student audiences.
\end{abstract}

Keywords-archetype; archetypal image; Chinese culture; colour scale of Chinese culture; representation of a road

\section{INTRODUCTION}

China today is witnessing a new wave of interest to Russian culture and Russian language at large. Lecturers from Russia to date work for over 80 Chinese universities. Such overseas employment permits teachers of Russian as a foreign language (RFL) to carry out various research among Chinese and Russian students, like the comparison of metaphors associated with some words.

Since "the event space", wherein the man lives, first translates itself, when describing, in visual patterns always coloured with the native speaker's national cultural sensitivity, and only after it crystallizes in verbal texts, the students mastering a foreign language come across the insights into the world that are likely to dramatically differ from their own one.

Mental aspects of the human consciousness point to the presence of a hidden deep stable public perception, to "the historically processed archetypical view of things, through the lens of which perception of the basic reality aspects is taking place" [1].

The archetypical content is expressed by mentality through the agency of a specific culture code. The archetype may be compared to a root, whereupon history and culture are producing new shapes and forms, colored with the entire scale of the man's psychic state" [2].

The existence of archetypical images manifests itself in the comparison, appearing under the action of the unconscious on associations concerned in the man's mind with contemporary events. An archetypical image is a part of representation, independent from the external sense, in which the archetype manifests itself.

The problems of learning a second language are that the learner's mind should develop a new system of semantic units "via mental representation of foreign-language symbols and their integration with corresponding the learning context emotions and representations, which constitute their psychological semantics" [3].

Therefore, in order to prevent forming students' representations that would be irrelevant to the target language's worldview, the RFL teacher has to realize, as far as possible, of course, all special aspects of the learners' mentality, the peculiarity of symbols and archetypal representations of their culture of origin.

\section{EXPERIMENT TO IDENTIFY THE EFFECT OF COLOUR SyMBOLISM OF NATIVE CULTURE WHILE VisuALIZING IMAGE OF A ROAD}

\section{A. Questionnaire Survey among Chinese and Russian Audiences}

Particularly for this purpose a survey had been conducted at the Sanya University (Hainan), identifying particulars of a road as imagined by the Russian-learning young representatives of the Chinese culture. The latter had been offered to describe a supposed road landscape.

Since colour is brought to the human mind / subconscious not as a property of some particular object, but as an individual sensation associated with this world perception and with colour symbolism of native culture, one of the issues was: "What colour is a road that you see on your imaginary picture?"

Results of the conducted experiments on identifying psychological exemplification of the "road" representation by Russian and Chinese students can be found in the author's earlier articles "Association experiment as the method of discovering national and cultural content of word associations", "Psychological semantics and affective evaluation of mental representation of 'road' ('path') by Chinese students" and "Mental Representations of 'Road' and 'Path' at the Comparative Aspect" and other [4] [5] [6].

The present article deals with just one feature of the road representation - a roadway's colour specification - with a glance to the influence of the symbolism of colour and colour archetypes of the native culture on appearance of individual representations and imageries.

The survey findings show that students picture the road as follows: black -19 people, white -15 people, yellow (sometimes with indication "country road") - 13 people, 
grey ("concrete") - 12 people, green -5 people, red -2 people and pink -1 person.

Comparing these findings with those of the survey conducted among the Russian audience, it may be noted that, indeed, the Russian informants lack such ample colours in their colour representation of the roadway, but then their description includes brown (colour of a country road), mentioned by not one of the Chinese respondents.

To explain such seemingly strange finding (indeed it is evident for a Russian that country roads are of the earth colour, while the most part of Russia's soil is brown), it is prerequisite to retrospect to the ancient Chinese culture.

\section{B. Expression of the Native Culture Colour Symbolism in Chinese Students' Answers}

\section{1) The Ancient Chinese Five-stage Colour Scale}

Since the earliest times, there have always been five primary colours in China - black, white, yellow, green and red. The ancient Chinese five-stage colour scale covers the figurative hierarchy of symbols and presents a strict and structural system of aesthetic value.

According to Chinese mythology, the five primary colours are emblematic of the five primary elements: Blackwater, white - metal, yellow - earth, blue-green, turquoise wood and red - fire. (As we see, yellow in China's culture agrees with the colour of earth, therefore, roads are correspondingly pictured by Celestial Empire's inhabitants yellow).

The ancient Chinese assumed everything in nature was created by the five primary elements, they are the basis of all the things (colour is present within them, while black and white are the primary colours), and there are consistent relations between the colour and five primary elements' principle, which was consistent with Heavens' motion and Heavenly Tao.

\section{2) Position of Brown Colour in the Colour Scale of} Chinese Culture

At those times, colours other than the five primary ones had been ousted from the aesthetics of harmonic representations. The first philosophers asserted that the basic colours must not be mixed, since this would lead to death of the essence of colour and its beauty; and that eyes enjoy just five colours, while colours falling out of traditions patterns, should be discarded. Probably for that reason the brown colour, being absolutely natural, somewhat is ignored even by cotemporary young adults. The colours, emphasizing the symbolism of native culture, with distinct, express meaning, are taking the center stage.

Indeed, the surveyed Chinese students were colouring the road almost in accordance with their ancient tradition-a road can be black, white, yellow, green or red. (Interesting that colour names of tea varieties in Chinese also completely coincide with the aesthetics of the Ancient colour scale. Tea in China may be black, white, yellow, green and red, while in Russia there are just two defined colours of tea, which is black and green. At the same time, Russians and Chinese avoid the definition brown while naming products or describing a person. No one will say brown bread or brown coffee; the only options here would be black tea, black coffee, black bread and black chocolate. Description of a person also avoids using the natural name of this colour in palettes, and is substituted for more "poetic" accents such as nut-brown hair, hazel eyes, olive skin, etc.).

\section{3) Notation of Red and White in Chinese Culture}

In line with the described by the students colours of a road, it seems natural that a black road presents an asphalt road, a grey road makes a concrete road, a green one refers to trees, a yellow to the colour of earth in China's midland, while red may point to fertile red earth widely occurring in southern China.

However, here, of course, certain simplification is allowed. For careful study of this issue, it is necessary to give a long look at China's culture, philosophy, poetry, aesthetics, colour symbolism and other.

For instance, a red road may be attributed to philosophic and religious views of Taoism, the basis colour of which is vermilion, a shade of red. Vermillion was used in potions meant to rejuvenate by Taoist alchemists. Therefore, there is a clear symbolism of red in the poem "Li Sao" by the poem Qu Yuan:

\section{The desert threatful-quicksands - I bypassed aside,}

As Vermilion river suddenly blocks my way”

Qu Yuan The poem "Li Sao” [7].

In Chinese poetry the 'red dust' (probably, a brick dust or reddish shade of earth) is used to symbolize city life lead in isolation from nature, and also to indicate a broadly defined secular earthliness. This is, for instance, how the Chinese poet Liu Yuxi, living in the $9^{\text {th }}$ century, writes:

Lilac Road I go down to the capital,

Wiping red dust away from my face.

Admired flowers but there is no one now

To share these feelings with on my way»

"The Peach Blossoms in Xuandu Temple" [8].

The "white road" well comports with Tao, wherein Tao is the path transcending the human realm. White denotes death, nothingness, chill. In China's culture the pra-matter, prototype, beginingless and infinity are white.

\section{CONCLUSION}

As we see, the colour carries own semantic spiritual and social expression, acts as a symbol of specific ideas and value paradigms. Perception of colour offers the process of attaining a deeper meaning of the archetypes' images, somewhat canonized in one or another culture. The presence of different systems of the colour naming and colour symbols in separate languages proves the effect of native language on the pattern of colour classification. 
When we are talking about the Chinese culture, we should bear in mind that the colour here "plays a more important role in building the linguistic worldview, than in the language systems with non-hieroglyphic writing", and this is evidenced by its "numerous representations in the language and its deep historical and cultural content" [9].

According to T.A Morozova., such "analysis of the colour naming is essential for manifestation of the importance of colours in building a man's visual space and of conditionality of functioning in the language with respect to the historical and cultural heritage, and Chinese mentality" [5].

\section{REFERENCES}

[1] E.S. Elbakian, "Russian intellectuals: mentality and archetype", National interests, 2004, No.2, pp. 33-39.

[2] V.M. Storchak, "Archetype and mentality in the context of the study of religion", Thesis for the degree of candidate of philological sciences, M., 1997, p.96.

[3] O.I. Ulanovich, "Linguistic consciousness: structure peculiarities in the context of bilingualism", Reporter of Tomsk State University, Philology, 2010, №1, pp. 44-51.

[4] E.S. Mikitchenko, "Associative experiment as a way of finding national and cultural content of lexical associations" // Rusistika'99, International conference on the second anniversary of the Society of Vietnamese Experts in Russian Studies and on Teachers' Day in Vietnam, Moscow, PSRLI, 1999, p. 60.

[5] Mikitchenko E.S., Psychological semantics and affective evaluation of mental representation of 'road' ('path') by Chinese students. Russian language in multicultural space: monograph. M.: RosNOU, 2014, p. 206.

[6] E. Mikitchenko, Mental Representations of "Road" and "Path" at the Comparative Aspect // Proceedings of the International Conference on Education, Language, Art and Intercultural Communication (ICELAIC 2014). Advances in Social, Education and Humanities Research, vol. 3, Zhengzhou, China, 5-7 May 2014, Atlantis Press, p. 432 .

[7] M.E. Kravtsova, The Literature of China Reader, SPb., Azbuka Publishing, 2004, p. 70.

[8] T.A. Morozova, "Historical semantics and symbolism of red in Chinese language", Journal of scientific publications of postgraduate and doctoral students, 2008, No.2, pp. 121-123.

[9] T.A. Morozova, "The colour sphere of concepts in the Chinese linguistic world image", Thesis for the degree of candidate of philological sciences: specialty 10.02.12, Kemerovo, 2008, p. 22. 